\title{
Capacitação em Tecnologias Digitais para Educação: uma ação de enfrentamento ao Ensino Remoto Emergencial na UFSM
}

Keiciane Canabarro Drehmer-Marques- UFSM- keicibio@gmail.com- 0000-0002-5338-8534

José Francisco Zavaglia Marques -UFRGS- franciscoquimica12@gmail.com -0000-0002-7866-112X

Daniele da Rocha Schneider- UFSM- dani.qmc@gmail.com- 0000-0003-4823-8133

Rosiele Oliveira da Encarnação -UFSM- rosiele_oliveira@live.com- 0000-0002-4314-5897

Silvana Zancan- UFN- silvanazancanufsm@gmail.com-0000-0003-4203-1772

Liziany Müller UFSM- lizianym@cead.ufsm.br-0000-0001-7325-6611

Resumo: Este artigo apresenta e discute as ações realizadas na capacitação de fluência tecnológica para o planejamento de atividades para o ensino remoto, implementadas em 2020 e 2021, na Universidade Federal de Santa Maria. Este estudo tem a finalidade de apresentar e discutir as ações realizadas por meio dos cursos de capacitações de fluência tecnológica, oferecidos aos servidores da UFSM, a fim de dar continuidade às atividades de ensino-aprendizagem no formato remoto. A organização metodológica, baseada no Design Based Research, envolveu a produção e a disponibilização de tutoriais em vídeos e arquivos, fóruns de discussões e momentos síncronos semanais. Os resultados dos feedbacks apontam que a capacitação contribuiu para a atualização de estratégias metodológicas, o aperfeiçoamento das atividades remotas administrativas e de ensino, qualificando, assim, com a fluência digital dos servidores da UFSM, participantes dos cursos.

Palavras-chave: COVID-19. Ensino Remoto Emergencial. Fluência digital.

\section{Training in Digital Technologies for Education: an action to confront Emergency Remote Education at UFSM}

\begin{abstract}
This article presents and discusses the actions carried out in the training of technological fluency for planning activities for remote education, implemented in 2020 and 2021, at Federal University of Santa Maria. This study aims to present and discuss the actions carried out through the technological fluency training courses offered to UFSM servers, in order to continue the teaching-learning activities in the remote format. The methodological organization, based on Design Based Research, involved the production and availability of tutorials in videos and files, a discussion forum and weekly synchronous moments. The results of the feedbacks indicate that the training contributed to update methodological strategies, improve remote administrative and teaching activities, qualifying the digital fluency of UFSM servers participating of the courses.
\end{abstract}

Keywords: COVID-19. Emergency Remote Teaching. Digital fluency.

\section{Introdução}

No ano de 2020, fomos surpreendidos pela expansão da COVID-19, essa doença que se iniciou em dezembro de 2019 e tomou proporções pandêmicas, afetando todos os continentes. Devido a sua rápida propagação e letalidade no ano de 2020, as atividades presenciais de instituições de ensino do Brasil foram suspensas e as aulas remotas foram vistas como uma possível estratégia para tal enfrentamento. A propagação da COVID-19 acelerou, de modo intenso, o uso das Tecnologias Digitais, entretanto, os diferentes 
setores educacionais, culturais, econômicos e sociais não estavam preparados para essa rápida modificação (ARRUDA, 2020).

A alteração de atividades presenciais para a forma remota no ensino foi autorizada pelo Ministério da Educação, pelas Portarias n 343, 345, 473, as quais foram revogadas, posteriormente, pela Portaria $\mathrm{n}^{\circ}$ 544, de 16 de junho de 2020 (BRASIL, 2020a), que dispunha sobre a substituição das aulas presenciais por aulas em meios digitais, enquanto durar a pandemia do COVID-19. Somado a essas iniciativas, o Conselho Nacional de Educação (CNE) aprovou a Resolução CNE/CP $\mathrm{n}^{\circ}$ 2, de 10 de dezembro de 2020 (BRASIL, 2020b), que estabelece normas educacionais excepcionais a serem adotadas pelos sistemas de ensino, instituições e redes escolares, públicas, privadas, comunitárias e confessionais, durante o estado de calamidade.

Conforme Arruda (2020), a educação ocorrer de forma remota não é uma escolha, mas uma necessidade, até que ocorra um possível retorno presencial. Em decorrência dessa realidade, o uso de tecnologias digitais é inevitável e sua utilização apresenta inúmeros benefícios. Contudo, quando imposta de forma abrupta e, como em alguns casos, meio exclusivo de ensino, causa desconforto e uma série de dificuldades, tanto aos docentes, quanto aos discentes (ALBUQUERQUE; GONÇALVES; BANDEIRA, 2020).

Perante a situação pandêmica a qual vivemos, estamos detectando a carência dos saberes de tecnologias educacionais por parte dos educandos e educadores, justificando a indispensabilidade de formações voltadas às influências tecnológicas. Para Arruda (2020, p. 272): "o Brasil não possui iniciativas no campo de tornar as tecnologias digitais como saberes necessários para uma formação transversal". Tal contexto denota a urgência de investir em formações voltadas às tecnologias digitais para fins educacionais.

Diante do exposto, o projeto "Fluência tecnológica no AVEA Moodle para o planejamento de disciplinas no ensino remoto" surgiu frente à necessidade de amparo aos servidores da Universidade Federal de Santa Maria (UFSM), para enfrentamento do Ensino Remoto Emergencial (ERE), a partir da Resolução N. 024, de 11 de agosto de 2020, que regulamenta o Regime de Exercícios Domiciliares Especiais (REDE). O projeto teve como objetivo promover a fluência tecnológica dos servidores da UFSM, em vários aplicativos e ferramentas digitais, como: ambiente virtual de ensino aprendizagem Moodle, sites, programas, aplicativos e demais recursos e ferramentas para o planejamento e o desenvolvimento de disciplinas e outras atividades no ensino remoto.

Nesse sentido, este estudo tem a finalidade de apresentar e discutir as ações realizadas por meio dos cursos de capacitações de fluência tecnológica oferecidos aos servidores da UFSM, a fim de dar continuidade às atividades de ensino-aprendizagem. Desta forma, o artigo divide-se em cinco seções, sendo a primeira, a introdução. Na segunda, problematizamos o potencial das tecnologias digitais no contexto educacional e a necessidade de desenvolvimento de fluência tecnológica. Na terceira, a metodologia aplicada e, em seguida, os resultados. Por fim, apresentamos as considerações finais.

\subsection{Fluência Tecnológica: implicações para o uso das tecnologias digitais no ensino}

O potencial de implementação das tecnologias digitais no ensino, diante da diversidade de sites, softwares e aplicativos que podem ser usados em sala de aula, requer o desenvolvimento de fluência tecnológica. O docente fluente tecnologicamente tem possibilidade de avaliar e selecionar as melhores ferramentas digitais, identificar suas limitações e possibilidades antes de seu uso.

"Ser fluente é pessoal no sentido de que os indivíduos fluentes com tecnologias da informação avaliam, distinguem, aprendem e usam novas tecnologias da informação, conforme apropriado para suas atividades pessoais e profissionais" (National Research 
Council, 1999, p. 6-7, tradução própria). Adquirir fluência com as tecnologias envolve desenvolver habilidades contemporâneas, capacidades intelectuais e conceitos fundamentais. Os conceitos fundamentais referem-se aos conhecimentos técnicos, em relação às ferramentas e seus benefícios. As habilidades contemporâneas capacitam o professor em relação a tudo que é possível criar com as tecnologias em rede e as capacidades intelectuais que envolvem ações de colaboração e abstração da informação. Conforme destaca Tarouco (2013, p. 288 -289):

\begin{abstract}
Habilidades contemporâneas implicam a capacidade de usar os aplicativos de computador atualmente disponíveis. Conceitos fundamentais consistem nos princípios básicos sobre computadores, redes e informações que constituem a base da tecnologia. Tais conceitos explicam a tecnologia, motivação e possibilidade de seu uso, bem como suas limitações. Capacidade intelectuais implicam as habilidades para aplicar a tecnologia da informação em situações complexas de forma continuada, manipulando os recursos tecnológicos para resolver problemas por mais inesperados que sejam. Isso demanda o uso de pensamento abstrato sobre a informação e sua manipulação.
\end{abstract}

Dentro do contexto não só escolar, mas em toda a sociedade, estamos cercados de indivíduos nativos digitais, inseridos em uma nova cultura, denominada de cultura digital, contendo não só computadores, smartphones, assim como eletrônicos, como a inteligência artificial, entre outros lançamentos (RODRIGUES et al., 2014). Nesse sentido: "um nível de fluência é necessário para que se entenda o momento histórico, se faça uso produtivo de ferramentas e seja crítico quanto a suas práticas" (AMARAL; AMIEL, 2013, p. 03).

Os recursos digitais foram integrados em todos os segmentos sociais de modo que muitos não conseguem mais imaginar-se vivendo sem eles. Para Behar (2009, p. 33): "surgem como uma ferramenta capaz de potencializar a reestruturação de práticas pedagógicas, originando novas formas de pensar a respeito do uso da comunicação, da ciência da informação, da construção, do conhecimento e da sua integração com a realidade".

No contexto universitário, os recursos digitais estão presentes nos processos de planejamento de aulas, do currículo, do ensino, da realização da matrícula e da certificação. Assim, a escolha de ferramentas digitais, a fim de modificar o processo educacional, interfere no comportamento dos envolvidos no processo de ensino e aprendizagem, como professores e estudantes, e na forma que é feita a abordagem dos conteúdos. As novas tecnologias digitais trouxeram mudanças nas escolhas das ferramentas para o processo de ensino, tais como: o uso de vídeos, computadores, smartphones, aplicativos, projetor, entre outros recursos (KENSKI, 2015).

Todas essas possibilidades, em relação à inserção de tecnologias digitais no currículo, colocam o docente em constante desafio. Se faz necessário o desenvolvimento de fluência tecnológica para rever, atualizar e desenvolver novas aprendizagens das ferramentas, utilizando-as como apoio ao ensino, de forma mais eficiente, atraente e interessante, e, também, modificando o uso dos espaços e dos tempos das atividades presenciais e a distância na educação (MORAN, 2017; CERIGATTO; MACHADO, 2018).

Nessa perspectiva, a cultura digital oportunizou que os estudantes, antes vistos como receptores passivos de conteúdo, se tornem produtores de conteúdo, conectados por meio da internet, estabelecendo trocas e compartilhamento de materiais, realizando trabalhos colaborativos, acessando notícias e comunicando os conteúdos em diferentes culturas. Essa mudança didático-metodológica, em relação ao processo de ensino e de aprendizagem de uma abordagem educacional tradicional, em que o professor é o 
expositor e detentor do conteúdo, para uma abordagem mais construtivista, torna o docente um orientador e um colaborador do processo de construção do conhecimento de seus estudantes.

É preciso que as coordenações, os docentes e os discentes entendam como se dá e se constrói o processo de ensino em rede, vencendo a resistência de que a tecnologia digital não possa potencializar o ensino (CERIGATTO; MACHADO, 2018). Isto posto, o professor que desenvolve fluência tecnológica tem condições de planejar, avaliar e tomar decisões em relação à potencialidade das ferramentas digitais, valorizando a flexibilidade e a colaboração na construção do conhecimento.

\section{Percursos metodológicos}

A metodologia de pesquisa utilizada neste trabalho tem características qualitativas e intervencionistas baseada em Design-Based Research (DBR) ou Pesquisa Baseada em Design implementados em contextos reais de sala de aula, integrando a pesquisa a sua prática docente (COLLINS; JOSEPH; BIELACZYC, 2004). Além disso, a DBR é conhecida por ser interativa, por razão de ser planejada entre pesquisadores e professores (as) que se envolvem no processo de design e iterativa pela sua realização cíclica incluindo análise, design, intervenção e redesign (WANG; HANNAFIN, 2005). Sua implementação gera aprendizagem e experiências não só para os estudantes envolvidos, como para os pesquisadores, professores e gestores envolvidos para aprimoramento dos seus design e implementação, buscando adequar as ferramentas digitais, organização do curso, do material de apoio adequado para alcançar os objetivos e a avaliação de todo o processo.

Seguimos a organização de Herrington et al. (2007), a DBR em quatro etapas, sendo elas: A primeira etapa, a identificação do problema e o planejamento do design entre os pesquisadores e participantes; a segunda etapa, a implementação do design no desenvolvimento de soluções; a terceira, a análise e a avaliação das atividades para a elaboração da quarta etapa, o redesign da reestruturação e a reimplementação da formação proposta em uma nova oportunidade. No decorrer das implementações dos cursos planejados, foram identificadas as questões positivas e negativas visando uma qualificação no processo formativo, na organização dos cursos e do material de apoio apresentado.

O problema identificado para o planejamento foi o de como promover cursos de formação para servidores que apresentam diferentes níveis de fluência digital, de modo que possam auxiliar nas suas demandas do ensino remoto, acrescentando qualidade nos serviços gerais prestados e no ensino, com apoio de ferramentas digitais? A partir da identificação do problema no contexto, foi elaborado pela equipe de pesquisadores, composta por servidores e estudantes da mesma instituição, um conjunto de cursos online contendo tutoriais em vídeos, textos de apoio e encontros síncronos para esclarecer dúvidas ao vivo na plataforma do YouTube, compondo o design para ser implementado na próxima etapa.

Ao longo do projeto de fluência tecnológica foram desenvolvidos cinco cursos de capacitação independentes entre si com conteúdos específicos, abordando diferentes ferramentas e recursos educacionais (Figura 1). Em cada curso foram liberadas 250 vagas e os servidores participantes receberam certificação de 60 horas, por curso. 


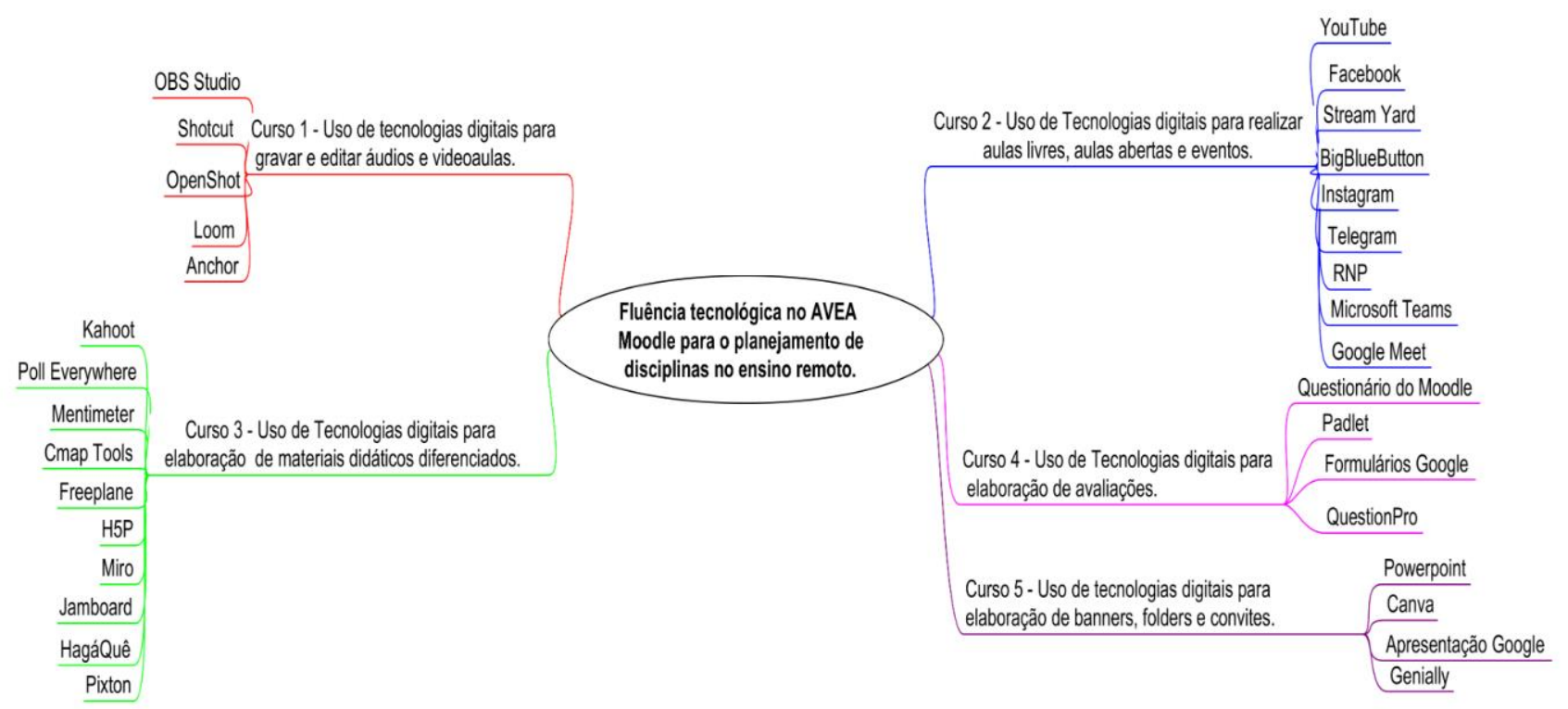

Figura 1. Mapa mental com os temas, as ferramentas e os recursos abordados em cada curso de capacitação.

Assim, em cada curso ocorreu o design, com a produção de materiais de apoio por meio de vídeo tutorial e do tutorial em pdf das ferramentas apresentadas. Os arquivos foram disponibilizados no ambiente virtual de aprendizagem Moodle do curso. Além disso, ocorreram encontros virtuais síncronos, semanalmente, com duração de duas horas, nos quais, de forma reflexiva, problematizamos e exemplificamos práticas pedagógicas possíveis de serem desenvolvidas com cada ferramenta. Nesses encontros, os participantes interagiram via chat, enviando suas dúvidas e contribuições. As transmissões ao vivo ocorreram por meio do YouTube e pelo site do Farol da UFSM. Cabe destacar, que os vídeos tutoriais e encontros semanais permanecem salvos no canal do YouTube "Capacitação digital UFSM 1 " e no site do farol ${ }^{2}$. No Moodle, disponibilizamos um fórum de dúvidas e um fórum de registro de presença para os encontros remotos.

Durante a realização dos vídeos tutoriais e dos encontros ao vivo realizamos situações de práticas pedagógicas e administrativas de acordo com a potencialidade e características de cada ferramenta digital selecionada, sempre em sua versão gratuita. Alguns recursos virtuais foram direcionados para atividades colaborativas, de gamificação, construção de vídeos, áudios, imagens, apresentações de slides para as aulas com maior interação, produção de histórias em quadrinhos, assim como realizar avaliações de forma diversificada, interativa e com possibilidades de feedback para os estudantes.

A capacitação teve como público-alvo servidores, professores e TécnicoAdministrativos em Educação (TAEs) da UFSM, que receberam a certificação, conforme

\footnotetext{
${ }^{1}$ Disponível em: 〈https://www.youtube.com/channel/UCsLwe9HMnt27tSmMHXsUPzQ〉. Acessado em 4 mar. 2021. 2

Disponível em: < https://farol.ufsm.br/produtor/37>. Acessado em 4 mar. 2021
} V. $19 \mathrm{~N}^{\circ}$ 1, julho, 2021 
critérios baseados na participação mínima de 50\% nos encontros remotos e acesso aos materiais do ambiente virtual de aprendizagem. No ambiente virtual, foi disponibilizado um fórum de dúvidas e um de registro de presença para os encontros remotos. Também foram inseridos os tutoriais em formato de vídeo e pdf, anterior aos encontros síncronos, para que os cursistas conhecessem e tivessem acesso às ferramentas digitais.

Para a divulgação do projeto, foi realizada a criação da página no Facebook (https://www.facebook.com/capacitacaodigitalufsm), no Instagram (@ capacitacaodigitalufsm) e um canal no YouTube. Assim, divulgamos convites para inscrições, encontros remotos e outros materiais informativos referentes aos cursos. Ao final de cada curso, foi implementado um questionário, para que os cursistas avaliassem o mesmo e, assim, os pesquisadores pudessem analisar e identificar os elementos que estão adequados e inadequados, que precisam ser modificados para sua próxima implementação, conhecida na DBR pelo redesign. O questionário de satisfação possuía 26 perguntas e foi separado por seções avaliando: o conteúdo, os instrutores, a interatividade, o ambiente virtual de ensino aprendizagem Moodle e aplicabilidade e resultados. Além dos dados quantitativos, elaboramos três questões abertas com espaço para críticas e sugestões, contribuição do curso para prática profissional e levantamento de opiniões sobre a relevância de cursos EaD para servidores da instituição. A fim de manter o anonimato, os participantes estão representados por códigos, conforme o exemplo: o código 1T1 compreende primeiro o número do curso 1 ao 5, segundo se é TAE (T) ou Docente (D) e por último o número de identificação.

\section{Resultados e Discussões}

O projeto "Fluência tecnológica no AVEA Moodle para o planejamento de disciplinas no ensino remoto", desenvolvido para auxiliar os servidores da UFSM na adaptação ao trabalho remoto, surgiu diante da problemática do uso emergencial do uso das tecnologias para uso em atividades do ensino. O projeto contou com 812 matriculados (Quadro 1), ao longo dos 5 cursos.

Quadro 1. Número de vagas, inscritos e aprovados por curso.

\begin{tabular}{|l|c|c|c|c|c|}
\hline Características & Curso 1 & Curso 2 & Curso 3 & Curso 4 & Curso 5 \\
\hline Vagas ofertadas & 250 & 250 & 250 & 250 & 250 \\
\hline Número de matriculados & 247 & 210 & 176 & 116 & 63 \\
\hline Docentes aprovados & 184 & 129 & 115 & 83 & 19 \\
\hline TAEs aprovados & 31 & 45 & 28 & 10 & 40 \\
\hline Total de aprovados & 215 & 174 & 143 & 93 & 59 \\
\hline
\end{tabular}

Fonte: autores, 2021.

O número considerável de concluintes, em relação ao número de vagas ofertadas, principalmente nos três primeiros cursos, com percentuais de $86 \%, 69,6 \%$ e 57,2\%, respectivamente, demonstrou o interesse e o comprometimento dos servidores com a formação acadêmica durante a pandemia. Surpreendidos pela interrupção das aulas V. $19 \mathrm{~N}^{\mathrm{o}} 1$, julho, 2021 DOI: https://doi.org/10.22456/1679-1916.118412 RENOTE 
presenciais e a adoção do Regime de Exercícios Domiciliares Especiais (REDE), os servidores precisaram se adaptar muito rapidamente ao modelo de ensino remoto e os cursos do projeto tornaram-se uma possibilidade para adquirir fluência tecnológica em recursos digitais. Entretanto, os cursos oferecidos 4 e 5 foram implementados em dezembro de 2020 e janeiro de 2021, respectivamente, fato que pode ter influenciado o menor número de inscritos, devido ao período coincidir com o final do semestre letivo, e, consequentemente, com uma maior demanda de trabalho obtivemos um dos menores percentuais de concluintes, comparado ao número de vagas ofertadas nos cursos 4 e 5 , com $37,2 \%$ e $23,6 \%$. No entanto, a porcentagem de aprovação, em relação ao número de inscritos, foi maior no curso 5 (93,7\%), ficando o curso 4 com aprovação de 80,2 \% , colocando-o entre o intervalo dos demais (C1- 87,0\%, C2- 82,9\% e C3- 81,2\%). Destacamos, que para obter a aprovação, o servidor deveria acessar o ambiente virtual de aprendizagem, além de participar de 50\% dos encontros virtuais, sendo que cada curso teve quatro encontros virtuais.

Considerando que o planejamento das aulas, mediadas pelas tecnologias, tornouse um desafio para muitos, os cursos implementados apresentaram um enfoque predominantemente prático, com uma diversidade de recursos capazes de "potencializar a reestruturação de práticas pedagógicas, originando novas formas de pensar a respeito do uso da comunicação, da ciência da informação, da construção, do conhecimento e da sua integração com a realidade" (BEHAR, 2009, p. 33). Essa variedade visou auxiliar no planejamento de aulas com maior qualidade para o ensino remoto, atendendo a Resolução N. 024, da UFSM, que traz como meta os desafios institucionais relacionados à Educação Inovadora e Transformadora com Excelência Acadêmica, Inclusão Social e Inovação, Geração de Conhecimento e Transferência de Tecnologia (PDI/UFSM, 2016-2026).

A oferta dos cinco cursos, de forma sequencial e independente, viabilizou o conhecimento das possibilidades e o domínio de cada recurso (PERRENOUD, 2000), além de possibilitar o redesign, em busca de soluções práticas à problemática que emergiu diante do contexto pandêmico. Essa solução prática envolve conhecimento técnico e pedagógico permitindo aos professores reconhecer, avaliar e tomar decisões em relação à ferramenta considerando os objetivos e os conteúdos a serem propostos aos estudantes. Por meio das avaliações e do retorno de 236 participantes, foi possível verificar a contribuição dos cursos, por meio do interesse e permanência dos cursistas, dado que pode ser verificado pelo número de aprovados e comentários deixados na pesquisa de avaliação, como:

Contribuiu na elaboração do material para minhas aulas via REDE. (1D8)

O curso foi de grande valia para contribuir com as novas metodologias que foram incluídas no durante o período de pandemia. (3D2)

O curso trouxe possibilidades de avançar na qualidade das aulas. (1D24)

Pretendo empregar algumas ferramentas nas aulas, pois são de grande importância para a aprendizagem dos acadêmicos, além de tornar as aulas mais dinâmicas e participativas. (2D24)

Os fóruns de dúvidas disponibilizados no ambiente virtual do curso e as aulas síncronas, com possibilidade de interação através do chat, viabilizaram o desenvolvimento de fluência tecnológica nos recursos digitais. Em uma perspectiva intervencionista de DBR, os servidores foram instigados a utilizar os recursos, a partir dos tutoriais disponibilizados em vídeos e arquivos, além de compartilharem suas dúvidas, em um processo colaborativo de desenvolvimento do conhecimento. As dificuldades apresentadas eram analisadas e o retorno explicativo acontecia no formato 
de vídeo, áudio, texto ou representação, de acordo com as especificidades individuais. A aceitação e os resultados dos tipos de retorno em cada curso contribuíram para a análise e para o redesign da proposta do curso, assim como do design dos tutoriais disponibilizados e da apresentação dos encontros síncronos. Nesse sentido, verificamos a potencialidade que os cursos de capacitação tiveram, como ferramentas de apoio à comunicação dialógica de TAEs e na prática educativa dos docentes da UFSM, evidenciados nos comentários, a seguir:

Na gravação e edição de vídeos na assessoria de comunicação. (1T85)

Já estou utilizando os conhecimentos adquiridos em atividades remotas com alunos,

Desenvolvendo avaliações e atividades complementares ao estudo remoto. (4D6)

Estou organizando um webinário e foi muito útil para a confecção das mídias. (5D5)

Logo, foi percebido que os docentes, ao interagir com novas tecnologias, iniciaram um processo de incorporação dessas em suas práticas pedagógicas, principalmente, no que tange à dinâmica de comunicação já emergente da cibercultura e da necessidade de qualificar o ensinar e o aprender no ensino remoto. É possível diagnosticar que, por meio da comunicação ubíqua, o ensino remoto repercutiu na cultura e na educação de todas as etapas de ensino. Nessa conjuntura, destacamos as relações dialógicas que TAEs e professores estabeleceram em suas demandas de trabalho e as tornaram inerentes aos processos de comunicação e de formação via remoto. Quando se destaca a tecnologia na educação remete-se a compreender que ela não constitui linguagem sem ação dialógica e fluência digital, sendo ainda mais evidente nas diversas esferas de trabalhos administrativos e pedagógicos. Citamos um comentário de um dos participantes.

Gostei muito das ferramentas apresentadas, pois permitem uma maior interação entre docente e alunos, algumas ainda entre os alunos, além de deixar as aulas menos monótonas. (2D9)

Nessa lógica, Levy (2010) cita que para haver comunicação na esfera digital é necessário enviar mensagens, porém, encaminhá-las não significa comunicar. A comunicação está permeada de sentido e de significado, quando acontece a partilha de conhecimentos plurais. Ainda nessa questão de comunicação em diferentes tempos e espaços do ensino remoto, percebemos como esse movimento é importante para estabelecer aprendizagens significativas, tanto por parte da equipe de capacitação, quanto dos cursistas, que expressavam constantemente suas opiniões e dúvidas sobre as tecnologias. Durante os encontros síncronos, identificamos, nas mensagens via chat, um engajamento por parte dos cursistas, com o objetivo de compreender as tecnologias e utilizá-las como estratégias didático-metodológicas no contexto educacional, na direção de criar uma dinâmica responsiva, reflexiva e multidimensional no ensino remoto. Destacamos, também, que os professores compreenderam a importância de pensar os materiais produzidos, a partir da utilização de novas tecnologias de apoio.

Contribui para a melhoria de produtividade através do conhecimento de vários recursos disponíveis para a execução das atividades. (1T80)

O curso contribui muito para o desempenho de minhas atividades administrativas e para a criação de materiais didáticos diversificados voltados ao ensino de Língua Inglesa. (3T45) 
Essa constatação está pautada pela necessidade que os cursistas tiveram em tornar suas práticas pedagógicas no ensino remoto mais atrativas, e, também, como meio de [re]significar e atender as demandas que emergiram e atravessaram as ações e as atividades de ensino, pesquisa, extensão e gestão. Assim, com a necessidade de aprender a trabalhar e se comunicar por meio das tecnologias digitais e educacionais, o ensino remoto motivou um grupo de estudantes da pós-graduação, de professores efetivos, de professores voluntários e de TAEs a criar um projeto de extensão, que atendesse as principais demandas que emergiram com a pandemia da COVID-19 à comunidade da UFSM.

Avaliando os relatórios referentes aos feedbacks dos participantes e as observações levantadas pelo grupo de pesquisadores para um futuro redesign, identificamos os pontos que precisam ser revistos e aprimorados, tais como: maior tempo de trabalho com cada ferramenta apresentada, inserção de atividades práticas e avaliativas. Além disso, realizar ofertas de cursos anualmente, buscando melhorias, pois os sites, programas e aplicativos utilizados sofrem atualizações constantemente, e, assim, os tutoriais tornam-se desatualizados.

\section{Considerações Finais}

A capacitação "Fluência tecnológica no AVEA Moodle para o planejamento de disciplinas no ensino remoto", implementada em 2020 e 2021, na Universidade Federal de Santa Maria, possibilitou aos servidores dessa instituição compreenderem as principais tendências, contribuições e desafios das tecnologias, tanto no ensino remoto, como na educação a distância. Como resultados, apontamos ser necessária a inserção das tecnologias digitais e educacionais, a partir do planejamento, formação prévia e continuada dos TAEs e professores da instituição de ensino. O projeto atingiu o objetivo proposto, pois promoveu a fluência tecnológica dos servidores participantes dos cursos, com a apresentação de diversas ferramentas digitais como alternativas viáveis para as atividades no ensino remoto. A iniciativa teve por objetivo secundário evitar o sentimento de impotência frente à cibercultura e à aplicação de estratégias pré-planejadas na educação.

Além disso, apontamos que os aplicativos e as ferramentas demonstradas durante os cursos de capacitação qualificaram a prática pedagógica dos professores e [re]significaram a visão de como acontece a comunicação dialógica no ambiente virtual de aprendizagem, nesse caso o ensino remoto. Dessa forma, a capacitação contribuiu para o aperfeiçoamento das atividades remotas, a atualização de estratégias metodológicas e a melhoria no desempenho de atividades administrativas, contribuindo, assim, para um processo de ensino e de aprendizagem de maior qualidade.

O desenvolvimento e a implementação dos cursos com os servidores da UFSM proporcionaram perspectivas futuras, após avaliações e validações dos mesmos, possibilitando um redesign dos cursos, de forma que esses sejam implementados aos docentes da Educação Básica, para auxiliar no ensino remoto. Por fim, pretendemos continuar com o desenvolvimento de cursos que possibilitem o aprimoramento dos docentes e demais sujeitos atuantes no campo do ensino, principalmente, quanto à fluência em tecnologias para educação.

\section{Referências}


ALBUQUERQUE, A.; GONÇALVES, T.; BANDEIRA, M. A formação inicial de professores: os impactos do ensino remoto em contexto de pandemia na região Amazônica. EmRede-Revista de Educação a Distância, v. 7, n. 2, p. 102-123, 2020.

AMARAL, S. F.; AMIEL, T. Nativos e Imigrantes: questionando o conceito de fluência tecnológica docente. Revista Brasileira de Informática na Educação, v. 21, n. 3, 2013. Disponível em: https://www.br-ie.org/pub/index.php/rbie/article/view/1661. Acesso em: 20 mar. 2021.

ARRUDA, E. P. Educação remota emergencial: elementos para políticas públicas na educação brasileira em tempos de Covid-19. Em Rede-Revista de Educação a Distância, v. 7, n. 1, p. 257-275, 2020.

BEHAR, P. A. (orgs). Modelos Pedagógicos em Educação a Distância. Porto Alegre: Artmed, 2009.

BRASIL. Ministério da Educação. Portaria $n^{\circ}$ 544, de 16 de junho de 2020. Revoga as Portarias MEC $\mathrm{n}^{\circ}$ 343, de 17 de março de 2020, nº 345, de 19 de março de 2020, e $\mathrm{n}^{\circ} 473$, de 12 de maio de 2020. Diário Oficial da União: seção 1, Brasília, DF, ed. 114, seção 1, p. 62,17 jun. 2020 a.

BRASIL. Ministério da Educação. Resolução CNE/CP nº 2, de 10 de dezembro de 2020. Institui Diretrizes Nacionais orientadoras para a implementação dos dispositivos da Lei $\mathrm{n}^{\mathrm{o}}$ 14.040, de 18 de agosto de 2020. Diário Oficial da União, de 10 de dezembro de 2020, Seção 1, pág. 106, 11 dez. 2020 b.

CERIGATTO, M. P.; MACHADO, V. G. Tecnologias digitais na prática pedagógica. [Digite o Local da Editora]: Grupo A, 2018. 9788595028128. Disponível em: https://integrada.minhabiblioteca.com.br/\#/books/9788595028128/. Acesso em: 10 fev. 2021.

COLLINS, A.; JOSEPH, D.; BIELACZYC, K. Design research: theoretical and methodological issues. Journal of the Learning Sciences, Madison, v. 13, n. 1, p. 1542, 2004.

HERRINGTON, J.; MCKENNEY, S.; REEVES, T. C.; OLIVER, R. Design-based research and doctoral students: Guidelines for preparing a dissertation proposal. In: EdMedia+ Innovate Learning. Association for the Advancement of Computing in Education (AACE), 2007. p. 4089-4097.

KENSKI, V. M. Educação e tecnologias: O novo ritmo da informação. Campinas, SP: Papirus, 2015.

LÉVY, P. Cibercultura. 3a . ed. Coleção TRANS. Rio de Janeiro: Editora 34, 2010.

MORAN, J. Tecnologias digitais para uma aprendizagem ativa e inovadora [pdf online]. Disponível em: http://www2.eca. usp.br/moran/wpcontent/uploads/2017/11/tecnologias_moran.pdf, 2017. Acesso em: 
NATIONAL RESEARCH COUNCIL. Being Fluent with Information Technology. Washington, DC: The National Academies Press. 1999. Disponível em: http://www.nap.edu/catalog/6482.html\&gt. Acesso em: 20 mar. 2021.

PERRENOUD, P. Dez novas competências para ensinar. Porto Alegre: Artes Médicas Sul, 2000.

ZEDNIK, H.; TAROUCO, L. M. R.; KLERING, L.; GARCÍA-VALCÁRCEL, A.; GUERRA, E. P. M. Tecnologias Digitais na Educação: proposta taxonômica para apoio à integração da tecnologia em sala de aula. In: Anais do Workshop de Informática na Escola. 2014. p. 507. Disponível em: https://brie.org/pub/index.php/wie/article/view/3135. Acesso em: 16 abr. 2021.

TAROUCO, L. M. R. Um panorama da fluência digital na sociedade da informação. In: BEHAR, P. A. (Org.). Competências em Educação a Distância. Porto Alegre: Penso, 2013.

UFSM. Universidade Federal de Santa Maria. Plano de Desenvolvimento Institucional 2016-2026. Disponível em: http://coral.ufsm.br/pdi/images/DocPDI/00-DocumentoPDITextoBaseCONSU.pdf. Acesso em: 20 mar. 2021.

UFSM. Universidade Federal de Santa Maria. Resolução N. 024, de 11 de agosto de 2020. Regula o Regime de Exercícios Domiciliares Especiais (REDE) e outras disposições afins, durante a Suspensão das Atividades Acadêmicas Presenciais em face da Pandemia da COVID-19. Disponível em: https://www.ufsm.br/proreitorias/proplan/resolucao-n-024-2020/ Acesso em: 20 mar. 2021.

WANG, F.; HANNAFIN, M. Design-Based Research and Technology-Enhanced Learning Environments. Educational Technology Research and Development, v. 53, n. 4, 2005. Disponível em: https://link.springer.com/article/10.1007/BF02504682\#citeas. Acesso em: 20 mar. 2021. 